\title{
Therapeutic strategies to improve drug delivery across the blood-brain barrier
}

\author{
Tej D. Azad, BA, James Pan, BS, lan D. Connolly, MS, Austin Remington, BA, \\ Christy M. Wilson, PhD, and Gerald A. Grant, MD \\ Department of Neurosurgery, Stanford University School of Medicine, Stanford, California
}

\begin{abstract}
Resection of brain tumors is followed by chemotherapy and radiation to ablate remaining malignant cell populations. Targeting these populations stands to reduce tumor recurrence and offer the promise of more complete therapy. Thus, improving access to the tumor, while leaving normal brain tissue unscathed, is a critical pursuit. A central challenge in this endeavor lies in the limited delivery of therapeutics to the tumor itself. The blood-brain barrier (BBB) is responsible for much of this difficulty but also provides an essential separation from systemic circulation. Due to the BBB's physical and chemical constraints, many current therapies, from cytotoxic drugs to antibody-based proteins, cannot gain access to the tumor. This review describes the characteristics of the BBB and associated changes wrought by the presence of a tumor. Current strategies for enhancing the delivery of therapies across the BBB to the tumor will be discussed, with a distinction made between strategies that seek to disrupt the BBB and those that aim to circumvent it.
\end{abstract}

http://thejns.org/doi/abs/10.3171/2014.12.FOCUS14758

KEY WORDS blood-brain barrier; focused ultrasound; convection-enhanced delivery; P-glycoprotein

$\mathrm{M}$ ANAGEMENT of most primary brain tumors includes maximal safe resection or biopsy followed by radiation and chemotherapy to target the remaining and potentially invasive tumor cells. However, delivering effective adjuvant treatment to these residual cell populations without damaging physiological brain tissue is a major challenge. One critical obstacle to effective treatments is the blood-brain barrier (BBB). This dynamic structure protects the CNS from environmental toxins and mediates physiological responses, effectively isolating the brain from the systemic circulation. Although many of the constituent cells and molecules of the BBB manifest throughout the body, in the brain they are combined into a unique construction that severely restricts entry into the brain.

Improved drug delivery stands to enhance existing treatments, mediate tumor recurrence, and provide an opportunity to therapeutically target tumors not amenable to resection. Thus, the motivation to enhance drug delivery is powerful and has led to the development of diverse meth- odologies to target and evade the $\mathrm{BBB}$. In this review, we discuss normal $\mathrm{BBB}$ physiology and pathological changes wrought by tumors, and detail therapeutic methods to disrupt, modulate, and circumvent the BBB.

\section{Blood-Brain Barrier and Tumor-Associated Changes}

The BBB refers to both passive and active mechanisms used by the brain endothelium to regulate access to the brain. This barrier is modulated in the context of brain tumors, evidenced by the penetration of Gd through the $\mathrm{BBB}$ on MRI of patients with glioblastoma.${ }^{98}$ Gadolinium enhancement increases as a function of WHO grade of astrocytoma, suggesting that $\mathrm{BBB}$ dysfunction is related to increasing histological grade in astrocytomas. ${ }^{66}$ Although $\mathrm{BBB}$ dysfunction is observed in many gliomas, the disruption is often heterogeneous and the vasculature remains grossly intact in brain regions where infiltrating cells are found, underscoring the need for tumor-specific methods

ABBREVIATIONS ABC = ATP-binding cassette; $A Q P 4=$ aquaporin-4; $B B B=$ blood-brain barrier; $C E D=$ convection-enhanced delivery; $E C M=$ extracellular matrix; FUS = focused ultrasound; P-gp = P-glycoprotein; WGA = wheat germ agglutinin; $Z O=$ zona occludens .

SUBMITTED November 1, 2014. ACCEPTED December 4, 2014.

INCLUDE WHEN CITING DOI: 10.3171/2014.12.FOCUS14758.

DISCLOSURE Dr. Grant is supported by a grant from the NIH (no. 7K08NS075144-04). 
to bypass the BBB. ${ }^{123}$ In this section we review the cellular structure of normal $\mathrm{BBB}$ and the impact of brain tumors on $\mathrm{BBB}$ coherence.

\section{Endothelial Cells, Tight Junctions, and Extracellular Matrix}

The BBB exists as a selective barrier formed by tight junctions between cerebral capillary endothelial cells, and is a critical regulator of brain homeostasis ${ }^{96}$ (Fig. 1). Endothelial cells in the cerebral vasculature share properties with peripheral endothelial cells but also have important differences. Small gaseous molecules such as $\mathrm{O}_{2}$ and $\mathrm{CO}_{2}$ can diffuse through the lipid membranes of the $\mathrm{BBB}$, as can small lipophilic molecules. However, the BBB tightly controls homeostasis by exclusion of harmful xenobiotics. One unique feature of brain endothelial cells is the existence of specific transport systems that regulate the entry of compounds necessary for brain metabolism, and chief among these are ATP-binding cassette (ABC) transporters. ${ }^{12,52} \mathrm{BBB}$ endothelial cells also have a lower number of endocytic vesicles and increased number of tight junctions, limiting transcellular and paracellular flow. Additionally, a host of intra- and extracellular enzymes provide further resistance by metabolizing substances ranging from peptides to toxic compounds. ${ }^{34}$
Tight junctions - the links between capillary endothelial cells - in the brain are more complex than those found in peripheral tissues and serve to prevent paracellular diffusion. Two critical components of these tight junctions are occludins and claudins. Occludins are 60- to $65-\mathrm{kD}$ proteins involved in tight junction regulation that are capable of binding zona occludens protein 1 (ZO-1). ${ }^{129}$ Claudin-3, claudin- 5 , and potentially claudin- 12 contribute to the BBB's restriction of small ions; ${ }^{125}$ other key components include ZO-1, ZO-2, ZO-3, cingulin, and 7H6 (Fig. 2).

Wolburg et al. found that a key component of BBB tight junctions, claudin-3, is lost in glioblastoma. ${ }^{26}$ This finding implicated claudin-3 as an effector in the leakiness of glioblastoma vessels. There is further evidence implicating claudin- 1 loss in tumor microvessels, as well as downregulation of claudin-5 and occludin in hyperplastic vasculature. These perturbations result in a phenotypic change in BBB function due to leaky tight junctions and hyperpermeable endothelial cells. ${ }^{70}$

The extracellular matrix (ECM) is also modulated by tumors. Rascher et al. demonstrated that agrin, an important component of the BBB basal lamina, is absent if claudin-1, claudin-5, and occludin are downregulated.95 The authors also noted that loss of agrin correlated with

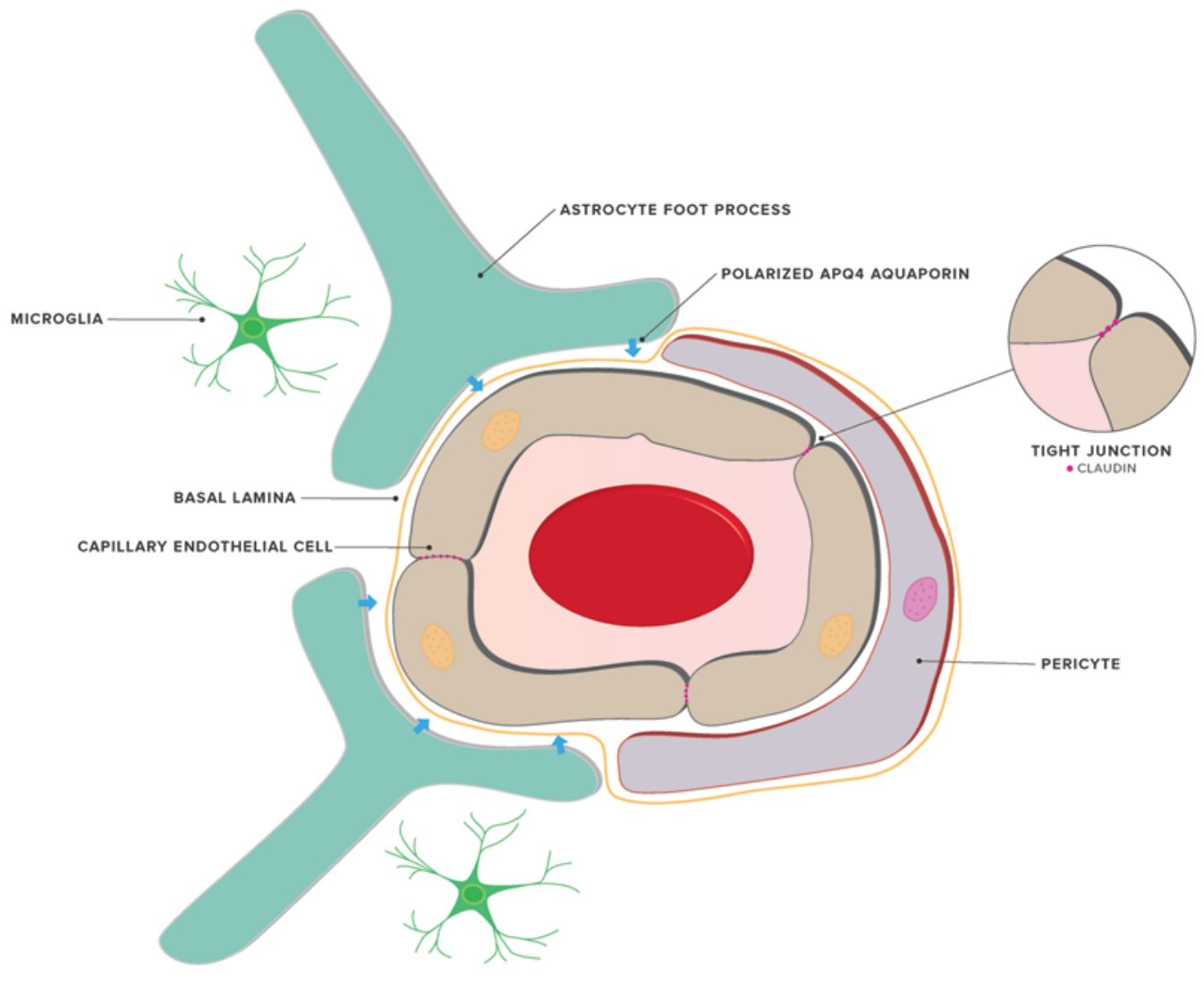

\section{NORMAL BLOOD BRAIN BARRIER}

FIG. 1. The normal, physiological BBB structure maintains strict control over CNS penetration. The major components of the BBB are cerebral endothelial cells bound together by tight junctions. The endothelium is surrounded by the basal lamina, pericytes, astrocytic endfeet, and microglia. These diverse cell types give rise to a dynamic environment that regulates entry into the brain. 


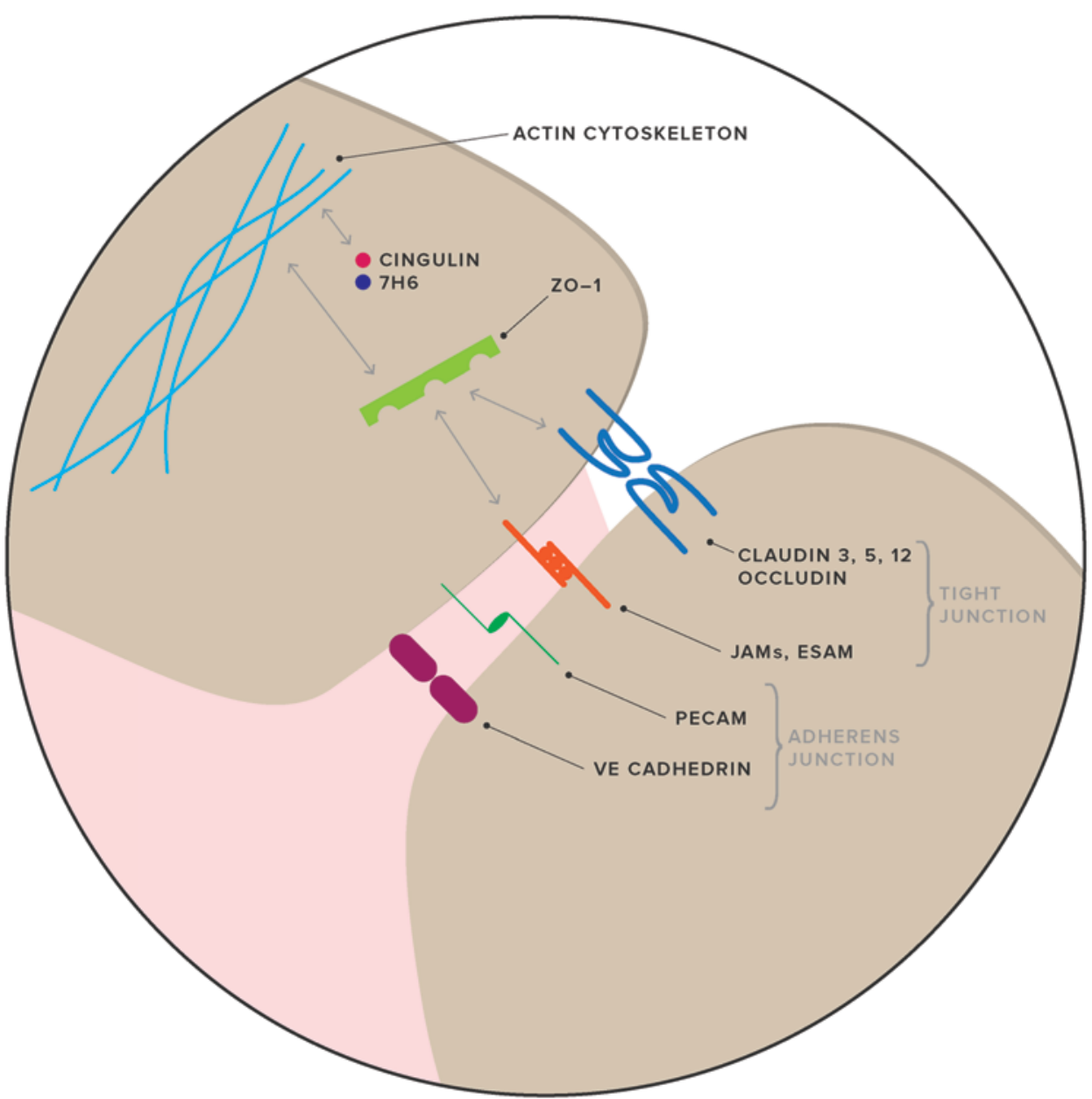

FIG. 2. Molecular composition of the cerebrovascular endothelial tight-junction structure. Claudins and occludin are critical junctional components. Two other components of the tight junction are junctional adhesion molecules (JAMs) and the endothelial selective adhesion molecule (ESAM). ZO-1 serves as an adaptor molecule in the cytoplasm with the ability to bind membrane proteins. Other important adaptor molecules are cingulin and $7 \mathrm{H} 6$. These adaptor proteins, in conjunction with other regulatory proteins, foster communication between membrane junctional molecules and the cytoskeleton. A second junctional complex is the adherens junction, consisting of vascular endothelial cadherin (VE-cadherin) and the platelet-endothelial cell adhesion molecule (PECAM).

upregulation of tenascin, an ECM molecule not normally expressed in brain vessels. Although the specific mechanisms underlying alterations in tight-junction and ECM components remain unclear, these correlative studies suggest some phenotypic relationship.

\section{Astrocytes}

The neurovascular unit is formed by endothelial cells surrounded by basal lamina and astrocytic endfeet. BBB maintenance is orchestrated by astrocytes, which serve as a cellular link to neurons. From studies of astroglial-endothelial co-culture, a number of receptors, transporters, and ligands have been identified that are involved in the bidirectional induction involved in BBB maintenance. ${ }^{2}$

Aquaporin-4 (AQP4) is an aquaporin water channel that is believed to have an important role in glioblastomarelated edema. Astrocytes express AQP4 and Warth et al. found that AQP4 redistribution is correlated with loss of agrin in cerebral capillary basal laminae in human glio- blastoma. The authors reported that the distribution of AQP4 shifted from the glial membrane in contact with mesenchymal space to cover the entire surface of glioma cells. ${ }^{118}$ In normal astrocytes, AQP4 is arranged as orthogonal arrays of particles, but this array arrangement is lost in glioblastoma. The functional consequence of this loss of astrocyte polarization is yet unknown, but the strong evidence for the role of astrocytes in glioblastoma makes this an important topic for further investigation.

A recent study by Watkins et al. used a mouse model to demonstrate that glioma cells displace astrocytic endfeet from their position alongside endothelial cells. This is a significant breach of the BBB that disrupts communication between the astrocytes and vasculature. Glioma cells were able to co-opt regulation of vascular tone. The authors demonstrated that single glioma cells were sufficient to produce local BBB opening. ${ }^{119}$ A study by Ndoum et al. demonstrated disruption of the astrocyte-endothelial cell association in intratumoral vessels in the enhancing regions of high-grade gliomas. Moreover, the authors 
found that low-grade gliomas, as well as the nonenhancing regions of high-grade gliomas, displayed intact astrocyte-endothelial cell relationships, as would be observed in unperturbed $\mathrm{BBB} .{ }^{82}$

\section{Pericytes}

Cerebral pericytes are an additional component of the BBB that occupy the perivascular space. In triculture experiments with endothelial cells and astrocytes, capillarylike structures are realized. Endothelial cells that form these structures in the presence of pericytes demonstrate resistance to apoptosis, supporting a stabilizing function of pericytes in angiogenesis. ${ }^{95}$ Further studies recapitulated the pericyte role in vascular tone, stability, repair, and angiogenesis ${ }^{64}$ as well as in modulation of astrocyte function. ${ }^{110}$

Abnormal pericyte distribution has been observed in established tumors. ${ }^{78}$ Given that brain pericytes can support BBB function through transforming growth factor- $\beta$ production, a role may exist for pericyte loss in gliomarelated $\mathrm{BBB}$ dysfunction. ${ }^{31} \mathrm{~A}$ more general role for pericytes in tumor vessel formation was highlighted by the discovery that glioblastoma stem cells can differentiate into pericytes during angiogenesis. ${ }^{25}$

\section{P-Glycoprotein}

A major player in maintaining the integrity and polarity of the BBB is through an efflux pump known as Pglycoprotein (P-gp). This $170-\mathrm{kD}$ transmembrane protein belongs to the $\mathrm{ABC}$ transporter family and is encoded by the $A B C B 1$ (or MDRI) gene. ${ }^{6}$ On the BBB, P-gp is localized on the apical membrane that facilitates transport in a unidirectional manner. ${ }^{38,112}$ The expression pattern of P-gp suggests that its normal physiological role is to protect the body from xenobiotic compounds by effluxing cytotoxic molecules into luminal spaces for elimination. A characteristic feature of P-gp is broad substrate specificity. A partial list of substrates in relation to CNS tumors is summarized in Table 1.

In addition to the normal physiological role of P-gp, overexpression of $\mathrm{P}-\mathrm{gp}$ is a feature common to many multidrug-resistant tumors. ${ }^{55,85} \mathrm{P}$-gp expression was demonstrated in glioma, and expression levels were correlated with multidrug resistance and tumor grade. ${ }^{44,68,74}$ In rela- tion to the BBB, P-gp activity is disrupted at the necrotic core of glioblastoma but preserved at the tumor border. ${ }^{28}$ This is clinically significant for glioblastoma following resection, because residual border cells with an intact barrier and potential P-gp overexpression limit drug uptake and often relapse into larger and more aggressive tumors. ${ }^{26}$

\section{Therapeutic Implications}

Early efforts to increase drug delivery to the brain have focused on disruption of key cellular components. However, disruptive efforts have become more refined and are joined by efforts to circumvent and modulate the BBB. In this section we detail current efforts in each of these therapeutic strategies.

\section{BBB Disruption}

\section{Osmotic Disruption}

The concept of hyperosmolar BBB disruption was first reported by Rapoport et al. in $1972 .{ }^{93}$ Following delivery of the hyperosmotic agent, water leaves endothelial cells, resulting in shrinkage and tight-junction dysfunction, leading to increased permeability of the BBB allowing for a therapeutic window of several hours. ${ }^{94} \mathrm{~A}$ variety of substances have been used as osmotic disruptors of the $\mathrm{BBB}$, but mannitol has been most commonly used for this

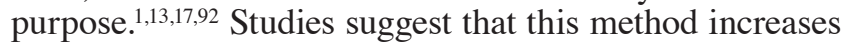
the concentrations of various chemotherapeutic agents in the brain up to 90 -fold. ${ }^{124}$ Furthermore, in a 1991 study of 30 patients with primary CNS lymphoma, BBB disruption via mannitol and cyclophosphamide before irradiation improved mean survival from 17.8 months to 44.5 months compared with controls receiving radiotherapy alone. ${ }^{83}$

There exists some debate regarding the effectiveness of this method due to conflicting reports about its differential effect on BBB permeability. Studies in multiple animal models reported that hypertonic solutions did not selectively disrupt the BBB local to the tumor. ${ }^{42,80,130}$ The increase in $\mathrm{BBB}$ permeability in a nonselective manner is problematic and raised concerns of systemic toxicity throughout the CNS. ${ }^{58}$ Nonetheless, recent studies support the method's safety and efficacy in humans. ${ }^{19,32}$ More work is needed to better understand the potential therapeutic value of this strategy.

TABLE 1. Summary of current FDA-approved pharmacological treatments for CNS tumors

\begin{tabular}{llcl}
\hline \multicolumn{1}{c}{ Drug } & \multicolumn{1}{c}{ Indications $^{*}$} & Molecular Weight (Da) & ABC Transporter Substrate \\
\hline Carmustine & Glioblastoma $^{37}$ & 214 & No \\
\hline Cisplatin & Medulloblastoma $^{40}$ & 300 & ABCC2, ABCC6 \\
\hline Cyclophosphamide & Medulloblastoma & 261 & No \\
\hline Etoposide & Glioblastoma & 588 & $A B C B 1$ \\
\hline Irinotecan & Glioblastoma & $586,623(\mathrm{HCl}), 677(\mathrm{HCl}$ trihydrate) & $A B C B 1$ \\
\hline Lomustine & Medulloblastoma, Grade III glioma ${ }^{108}$ & 233 & No \\
\hline Procarbazine & Grade III glioma & 221 & No \\
\hline Temozolomide & Glioblastoma & 194 & $A B C B 1$ \\
\hline Vincristine & Medulloblastoma, Grade III glioma & 824 & $A B C B 1$ \\
\hline Bevacizumab & Glioblastoma & 149,000 & No \\
\hline
\end{tabular}

* Treatment indications collected from the literature. . $^{37,40,108}$ 


\section{MRI-Guided Focused Ultrasound}

The feasibility of focused ultrasound (FUS) to disrupt the $\mathrm{BBB}$ was first demonstrated more than 10 years ago. ${ }^{48}$ Subsequent studies have confirmed FUS as a valuable method to introduce focal and transient BBB disruption. ${ }^{46,47}$ This technique has several advantages over other approaches because it is readily repeatable, noninvasive, and able to disrupt the BBB in a targeted way. Studies suggest that FUS may increase cerebrovascular permeability by producing shear stress in cells or by activation of signaling pathways involved in the regulation of permeability. ${ }^{41,51,115,116}$ The disruption of tight junction proteins by FUS may also contribute to this method's mechanism of action. ${ }^{104-106}$

The technique can be used in conjunction with intravenously administered microbubbles to lower the ultrasound energy required to induce $\mathrm{BBB}$ disruption. ${ }^{48}$ Nonhuman primate studies have shown that microbubble-enhanced FUS can successfully induce local BBB opening with minimal side effects. ${ }^{73,75,114}$ The safety of FUS therapy is promising as it is not associated with significant tissue damage. ${ }^{10,49,76}$ The use of MRI with FUS allows for the targeting and evaluation of BBB opening, ${ }^{48}$ and several groups have developed methods that aim to monitor acoustic emissions from microbubbles in real time..$^{7,53,57}$

Although this approach is in the preclinical phase, it is of high clinical relevance as various FDA-approved chemotherapy drugs such as doxorubicin, carmustine, trastuzumab, and temozolomide have been successfully introduced across the BBB through this approach. , $71,77,122$ Focused ultrasound has also been combined with nanoparticle platforms to enhance diagnostic and treatment capabilities. In the study by Diaz et al., gold nanoparticles were safely introduced to the tumor periphery with MRIguided FUS in a mouse brain tumor model, augmenting surface-enhanced Raman scattering capability. Furthermore, the authors demonstrated that nanoparticles coated with anti-epidermal growth factor receptor antibody or nonspecific human immunoglobulin-G had increased uptake in glioma cells. ${ }^{30}$

While FUS shows promise in animal models, a limitation is signal attenuation and distortion from the skull. A study in rabbits sought to measure BBB disruption by applying FUS directly to the brain surface through a device implanted in a skull bur hole. ${ }^{11}$ Further study is necessary to gauge the feasibility of this approach in humans.

\section{Bradykinin Administration}

Bradykinin administration has been shown to upregulate caveolin- 1 and caveolin- 2 at the $\mathrm{BBB} .^{72}$ The upregulation of these compounds serves to increase endothelial cell permeability, increasing the chance of appropriate drug delivery. The potential of bradykinin, and synthetic analogs, to disrupt the BBB has been widely explored. ${ }^{16,35,50,102}$ A central limitation is that the effect of the upregulation is exceedingly transient. ${ }^{72}$ One clinical trial showed minimal therapeutic benefit of using carboplatin with lobradimil, a synthetic bradykinin analog, to treat brain tumors in a pediatric population. ${ }^{117}$ A greater understanding of the cellular mechanisms at the BBB stands to improve the efficacy of administering bradykinin with chemotherapy drugs.

\section{Radiation-Induced Disruption}

The use of radiation therapy to induce DNA damage and subsequent cell death has become an important treatment modality for brain tumors. Recent innovations in radiation therapy have improved precision, tumor definition with imaging, and radiation delivery through beam shaping. ${ }^{24}$ In addition to its current utility, radiation therapy may play a role in selectively disrupting the BBB. Studies in both animals and humans have demonstrated that radiation therapy can induce focal $\mathrm{BBB}$ disruption with minimal effects on normal vasculature. ${ }^{23,67,86,89}$ These results suggest that $\mathrm{BBB}$ disruption may be an additional utility of radiation therapy.

\section{BBB Circumvention}

\section{Convection-Enhanced Delivery}

Convection-enhanced delivery (CED), first described by Bobo et al. in 1994, involves the use of surgically implanted catheters that enable continuous delivery of chemotherapy directly into the tumor through positive pressure microperfusion. ${ }^{18}$ Various antineoplastic agents, mostly immunotoxins, are under investigation for use through CED. ${ }^{59,62,84,100,107}$ Another approach involves chemotherapeutic delivery via CED of nanoparticles. ${ }^{14,128} \mathrm{Al}-$ though these studies have demonstrated effectiveness in vivo, more work must be conducted to investigate the longterm effects of potential accumulations of the nanoparticles in the brain. CED can be used following resection or to treat inoperable tumors. ${ }^{56}$ The major drawbacks of CED include operative risks and limited drug distribution due to backflow. ${ }^{91,101,111}$ Despite the promise of this novel approach in enhancing the delivery of therapeutics, its safety and efficacy has yet to be clearly determined, as several Phase III clinical trials have failed to meet clinical end points. $63,87,90,99,120,121$

\section{Viral-Mediated Circumvention}

Viral vectors to deliver therapeutic drugs have also been examined for glioblastoma treatment. The goal of these strategies is to specifically target tumor cells via cell surface receptors and use virus replication derivatives to combat cancer growth. The value of using viruses as vehicles is partly due to their small size, allowing for permeability across the BBB. Such methods also have promise in combating cancers that have acquired chemotherapy and drug resistance. In vivo studies with the measles virus demonstrated a cytopathic effect on glioma stem cells and prolonging survival in a mouse model. ${ }^{4}$ Viruses can be created with soluble peptide markers to monitor spread in vivo, and viral vectors may have synergistic activity when combined with conventional treatments, such as CED or radiation therapy. ${ }^{5,27,56}$ Adding an amphotropic retroviral replicating vector can similarly be used to target glioma cells. Toca 511, a retroviral replicating vector, has been shown to safely deliver a cytosine deaminase gene and improve survival for glioblastoma models in vivo. ${ }^{45}$ When combined with radiation therapy or CED, this approach has promise for future steps in combating glioblastoma growth. 


\section{Carrier Molecules}

Other treatment strategies aim to use carrier molecules to transport drugs across the BBB. In creating these compounds, the surface coating can be engineered to optimize transport and targeting abilities. Other factors such as core polymer, drug, and stabilizer formulation have also been shown to influence nanoparticle delivery. ${ }^{39}$ Particle systems such as poly(lactic-coglycolic acid) and dendrimer nanoparticles have been studied in the context of brain cancer. ${ }^{39}$ Another synthetic peptide, K16ApoE, carries chemotherapeutic compounds into the brain via a ligand-receptor system. ${ }^{103}$ Although it is difficult to accurately monitor dosage, as well as systemic toxicological effects, these systems offer greater promise for drug delivery. Studies have reviewed optimal nanoparticle sizing, but future research on ligand-receptor interactions at the $\mathrm{BBB}$ and the ideal surface characteristics of nanoparticle delivery mechanisms is necessary. ${ }^{81,127}$ Nanotherapeutic approaches also have used magnetic therapy to localize drug-carrying molecules. ${ }^{29}$ In this method, a carrier molecule with iron residues is guided to the tumor location with an external magnetic field. Such an approach is encouraging, as a drug can be administered directly to the brain and with sustained release. Advances in biomaterials will also be able to increase the half-life of the encapsulated drug, improving efficacy. ${ }^{29}$

\section{Liposomal Delivery}

Liposomes contain a drug of interest within a lipophilic vesicle, facilitating endocytosis and uptake into brain tissue. These compounds hold great promise for glioblastoma, offering more surface area for passive diffusion. Various liposome preparations have been explored and combined with CED in previous studies. ${ }^{43,60}$ Liposomal delivery has been extensively studied for doxorubicin, showing disease stabilization and low systemic toxicity. ${ }^{36}$ A recent study using a rat glioma model found that the surface charge of liposomes is a significant factor for deposition within the brain. ${ }^{54}$ The beneficial effect was noted independent of techniques disrupting BBB permeability, offering a safer and simpler method of administration. Other studies have added compounds such as wheat germ agglutinin (WGA) to the liposome surface. WGA has been shown to aid in adsorptive endocytosis in the BBB, as this glycoprotein binds to negatively charged residues in the epithelial membrane. ${ }^{33}$ Liposomes modified with WGA have been shown to reliably target glioma tumors both in vitro and in vivo, offering a possible area of research for glioblastoma treatment. ${ }^{69}$ Limitations of this delivery mechanism include the large size of liposomes and controlled release of the encapsulated drugs from the vesicles

\section{Polymer Wafers}

Polymer wafers that are implanted into the resection cavity after surgery allow for the localized administration of drugs that would otherwise be unable to access the tumor site due to the BBB. ${ }^{21,22}$ This approach has renewed interest in therapeutics originally believed to be of limited use due to their inability to penetrate the $\mathrm{BBB}$ or due to their toxicity. ${ }^{15}$ The Gliadel wafer (Eisai) is a critical example of this strategy and received FDA approval for use in 2003 for newly diagnosed and recurrent malignant gliomas. ${ }^{9,20,56,79}$ However, its use is not generally recommended as subsequent studies demonstrated marginally increased survival in patients with glioblastoma and a high incidence of associated complications such as seizures, cerebral edema, and infection. Bregy and colleagues reviewed 795 patients with newly diagnosed high-grade glioma treated with Gliadel wafers in 19 studies and reported an overall complication rate of $42.7 \% .^{20}$ Thus, more work must be completed to reduce complications associated with this approach and additional polymer delivery methods must be developed.

\section{P-gp Targeting and Modulation}

Modulation of specific surface proteins on capillary endothelial cells can offer more specific and less disruptive strategies to deliver drugs into the CNS. Pharmacological interventions often fail in the brain setting due in part to P-gp-mediated efflux of small molecules out of brain tissue back into the capillary lumen. Strategies have been developed to circumvent the $\mathrm{BBB}$ through either inhibition of P-gp or the modulation of its expression and/or trafficking.

Direct inhibition of P-gp through small molecules and other pharmaceutical methods have been initially met with limited efficacy and safety in a clinical setting; however, recent advances in drug discovery have elucidated promising new molecules with nanomolar specificity and acceptable tolerability. ${ }^{65,113}$ The most promising drug to result from this process is tariquidar, which binds $\mathrm{P}$-gp noncompetitively at nanomolar concentrations. ${ }^{97}$ This drug has been shown to sufficiently inhibit P-gp at the BBB in vivo. Kreisl et al. showed greater uptake of 11C-N-desmethylloperamide by PET, a known P-gp substrate. ${ }^{61}$ Acceptable tolerability is achieved in combination with dose-linear responses, tariquidar shows promise for inhibiting P-gp at the human BBB and allowing effective CNS drug delivery.

Pinzón-Daza et al. has elucidated the role of crosstalk between canonical and noncanonical Wnt pathways and its relationship to $\mathrm{P}-\mathrm{gp}$ expression in the human $\mathrm{BBB} .{ }^{88}$ The authors found that downregulation of $\beta$-catenin led to a decrease in $\mathrm{P}$-gp expression. It was also shown in vitro that the inhibition of $\beta$-catenin enhanced delivery of doxorubicin, a P-gp substrate, across a BBB epithelial monolayer against glioblastoma cells.

Modulation of P-gp has attracted much attention in disrupting the $\mathrm{BBB}$ in a noninvasive, specific, and rapid manner. However, despite numerous clinical trials involving P-gp inhibitors, none have been performed in any patients with primary or metastatic neoplasms of the CNS. ${ }^{109}$ Outcomes to explore would be whether co-administration of P-gp inhibitors along with chemotherapy can stop tumor growth and/or reduce tumor size, result in prolonged survival, and result in an outcome that avoids any long-term sequelae. ${ }^{3}$

\section{Conclusions}

A growing body of evidence implicates the BBB as critical in fully understanding brain tumor pathophysiology. Future studies hold potential for both fundamental bio- 
logical knowledge and for critical therapeutic discoveries. However, the question remains whether BBB disruption coupled with targeted therapy will improve patient survival. Several investigators across multiple disciplines are working collaboratively to improve the ability to penetrate the $\mathrm{BBB}$ to allow novel therapeutics to infiltrate further into the tumor and the surrounding brain.

\section{References}

1. Abbott NJ, Revest PA: Control of brain endothelial permeability. Cerebrovasc Brain Metab Rev 3:39-72, 1991

2. Abbott NJ, Rönnbäck L, Hansson E: Astrocyte-endothelial interactions at the blood-brain barrier. Nat Rev Neurosci 7:41-53, 2006

3. Agarwal S, Hartz AM, Elmquist WF, Bauer B: Breast cancer resistance protein and P-glycoprotein in brain cancer: two gatekeepers team up. Curr Pharm Des 17:2793-2802, 2011

4. Allen C, Opyrchal M, Aderca I, Schroeder MA, Sarkaria JN, Domingo E, et al: Oncolytic measles virus strains have significant antitumor activity against glioma stem cells. Gene Ther 20:444-449, 2013

5. Allen C, Paraskevakou G, Liu C, Iankov ID, Msaouel P, Zollman P, et al: Oncolytic measles virus strains in the treatment of gliomas. Expert Opin Biol Ther 8:213-220, 2008 (Erratum in Expert Opin Biol Ther 8:855, 2008)

6. Ambudkar SV, Lelong IH, Zhang J, Cardarelli CO, Gottesman MM, Pastan I: Partial purification and reconstitution of the human multidrug-resistance pump: characterization of the drug-stimulatable ATP hydrolysis. Proc Natl Acad Sci U S A 89:8472-8476, 1992

7. Arvanitis CD, Livingstone MS, Vykhodtseva N, McDannold $\mathrm{N}$ : Controlled ultrasound-induced blood-brain barrier disruption using passive acoustic emissions monitoring. PLoS ONE 7:e45783, 2012

8. Aryal M, Vykhodtseva N, Zhang YZ, Park J, McDannold N: Multiple treatments with liposomal doxorubicin and ultrasound-induced disruption of blood-tumor and blood-brain barriers improve outcomes in a rat glioma model. J Control Release 169:103-111, 2013

9. Ashby LS, Ryken TC: Management of malignant glioma: steady progress with multimodal approaches. Neurosurg Focus 20(4):E3, 2006

10. Baseri B, Choi JJ, Tung YS, Konofagou EE: Multi-modality safety assessment of blood-brain barrier opening using focused ultrasound and definity microbubbles: a short-term study. Ultrasound Med Biol 36:1445-1459, 2010

11. Beccaria K, Canney M, Goldwirt L, Fernandez C, Adam $\mathrm{C}$, Piquet J, et al: Opening of the blood-brain barrier with an unfocused ultrasound device in rabbits. J Neurosurg 119:887-898, 2013

12. Begley DJ, Brightman MW: Structural and functional aspects of the blood-brain barrier. Prog Drug Res 61:39-78, 2003

13. Bellavance MA, Blanchette M, Fortin D: Recent advances in blood-brain barrier disruption as a CNS delivery strategy. AAPS J 10:166-177, 2008

14. Bernal GM, LaRiviere MJ, Mansour N, Pytel P, Cahill KE, Voce DJ, et al: Convection-enhanced delivery and in vivo imaging of polymeric nanoparticles for the treatment of malignant glioma. Nanomedicine (Lond Print) 10:149-157, 2014

15. Biddlestone-Thorpe L, Marchi N, Guo K, Ghosh C, Janigro $\mathrm{D}$, Valerie K, et al: Nanomaterial-mediated CNS delivery of diagnostic and therapeutic agents. Adv Drug Deliv Rev 64:605-613, 2012

16. Black KL, Cloughesy T, Huang SC, Gobin YP, Zhou Y, Grous $\mathrm{J}$, et al: Intracarotid infusion of RMP-7, a bradykinin analog, and transport of gallium-68 ethylenediamine tetraacetic acid into human gliomas. J Neurosurg 86:603-609, 1997
17. Blanchette M, Pellerin M, Tremblay L, Lepage M, Fortin D: Real-time monitoring of gadolinium diethylenetriamine penta-acetic acid during osmotic blood-brain barrier disruption using magnetic resonance imaging in normal wistar rats. Neurosurgery 65:344-351, 2009

18. Bobo RH, Laske DW, Akbasak A, Morrison PF, Dedrick RL, Oldfield EH: Convection-enhanced delivery of macromolecules in the brain. Proc Natl Acad Sci U S A 91:2076-2080, 1994

19. Boockvar JA, Tsiouris AJ, Hofstetter CP, Kovanlikaya I, Fralin S, Kesavabhotla K, et al: Safety and maximum tolerated dose of superselective intraarterial cerebral infusion of bevacizumab after osmotic blood-brain barrier disruption for recurrent malignant glioma. Clinical article. J Neurosurg 114:624-632, 2011

20. Bregy A, Shah AH, Diaz MV, Pierce HE, Ames PL, Diaz $D$, et al: The role of Gliadel wafers in the treatment of highgrade gliomas. Expert Rev Anticancer Ther 13:1453-1461, 2013

21. Brem H, Piantadosi S, Burger PC, Walker M, Selker R, Vick NA, et al: Placebo-controlled trial of safety and efficacy of intraoperative controlled delivery by biodegradable polymers of chemotherapy for recurrent gliomas. Lancet 345:10081012,1995

22. Cao X, Schoichet MS: Delivering neuroactive molecules from biodegradable microspheres for application in central nervous system disorders. Biomaterials 20:329-339, 1999

23. Cao Y, Tsien CI, Shen Z, Tatro DS, Ten Haken R, Kessler $\mathrm{ML}$, et al: Use of magnetic resonance imaging to assess blood-brain/blood-glioma barrier opening during conformal radiotherapy. J Clin Oncol 23:4127-4136, 2005

24. Chacko AM, Li C, Pryma DA, Brem S, Coukos G, Muzykantov V: Targeted delivery of antibody-based therapeutic and imaging agents to CNS tumors: crossing the blood-brain barrier divide. Expert Opin Drug Deliv 10:907-926, 2013

25. Cheng L, Huang Z, Zhou W, Wu Q, Donnola S, Liu JK, et al: Glioblastoma stem cells generate vascular pericytes to support vessel function and tumor growth. Cell 153:139-152, 2013

26. Cheshier SH, Kalani MY, Lim M, Ailles L, Huhn SL, Weissman IL: A neurosurgeon's guide to stem cells, cancer stem cells, and brain tumor stem cells. Neurosurgery 65:237-250, 2009

27. Debinski W, Tatter SB: Convection-enhanced delivery to achieve widespread distribution of viral vectors: predicting clinical implementation. Curr Opin Mol Ther 12:647-653, 2010

28. Deeken JF, Löscher W: The blood-brain barrier and cancer: transporters, treatment, and Trojan horses. Clin Cancer Res 13:1663-1674, 2007

29. del Burgo LS, Hernández RM, Orive G, Pedraz JL: Nanotherapeutic approaches for brain cancer management. Nanomedicine (Lond Print) 10:905-919, 2014

30. Diaz RJ, McVeigh PZ, O’Reilly MA, Burrell K, Bebenek M, Smith C, et al: Focused ultrasound delivery of Raman nanoparticles across the blood-brain barrier: potential for targeting experimental brain tumors. Nanomedicine (Lond Print) 10:1075-1087, 2014

31. Dohgu S, Takata F, Yamauchi A, Nakagawa S, Egawa T, Naito M, et al: Brain pericytes contribute to the induction and up-regulation of blood-brain barrier functions through transforming growth factor-beta production. Brain Res 1038:208-215, 2005

32. Doolittle ND, Miner ME, Hall WA, Siegal T, Jerome E, Osztie E, et al: Safety and efficacy of a multicenter study using intraarterial chemotherapy in conjunction with osmotic opening of the blood-brain barrier for the treatment of patients with malignant brain tumors. Cancer 88:637-647, 2000

33. Du J, Lu WL, Ying X, Liu Y, Du P, Tian W, et al: Dual- 
targeting topotecan liposomes modified with tamoxifen and wheat germ agglutinin significantly improve drug transport across the blood-brain barrier and survival of brain tumorbearing animals. Mol Pharm 6:905-917, 2009

34. el-Bacha RS, Minn A: Drug metabolizing enzymes in cerebrovascular endothelial cells afford a metabolic protection to the brain. Cell Mol Biol (Noisy-le-grand) 45:15-23, 1999

35. Emerich DF, Snodgrass P, Pink M, Bloom F, Bartus RT: Central analgesic actions of loperamide following transient permeation of the blood brain barrier with Cereport (RMP7). Brain Res 801:259-266, 1998

36. Fabel K, Dietrich J, Hau P, Wismeth C, Winner B, Przywara $\mathrm{S}$, et al: Long-term stabilization in patients with malignant glioma after treatment with liposomal doxorubicin. Cancer 92:1936-1942, 2001

37. Fadul CE, Wen PY, Kim L, Olson JJ: Cytotoxic chemotherapeutic management of newly diagnosed glioblastoma multiforme. J Neurooncol 89:339-357, 2008

38. Fung KL, Pan J, Ohnuma S, Lund PE, Pixley JN, KimchiSarfaty C, et al: MDR1 synonymous polymorphisms alter transporter specificity and protein stability in a stable epithelial monolayer. Cancer Res 74:598-608, 2014

39. Gelperina S, Maksimenko O, Khalansky A, Vanchugova L, Shipulo E, Abbasova K, et al: Drug delivery to the brain using surfactant-coated poly(lactide-co-glycolide) nanoparticles: influence of the formulation parameters. Eur J Pharm Biopharm 74:157-163, 2010

40. Gerber NU, Mynarek M, von Hoff K, Friedrich C, Resch A, Rutkowski S: Recent developments and current concepts in medulloblastoma. Cancer Treat Rev 40:356-365, 2014

41. González-Mariscal L, Tapia R, Chamorro D: Crosstalk of tight junction components with signaling pathways. Biochim Biophys Acta 1778:729-756, 2008

42. Groothuis DR, Warkne PC, Molnar P, Lapin GD, Mikhael MA: Effect of hyperosmotic blood-brain barrier disruption on transcapillary transport in canine brain tumors. J Neurosurg 72:441-449, 1990

43. Gupta B, Levchenko TS, Torchilin VP: TAT peptide-modified liposomes provide enhanced gene delivery to intracranial human brain tumor xenografts in nude mice. Oncol Res 16:351-359, 2007

44. Henson JW, Cordon-Cardo C, Posner JB: P-glycoprotein expression in brain tumors. J Neurooncol 14:37-43, 1992

45. Huang TT, Hlavaty J, Ostertag D, Espinoza FL, Martin B, Petznek H, et al: Toca 511 gene transfer and 5-fluorocytosine in combination with temozolomide demonstrates synergistic therapeutic efficacy in a temozolomide-sensitive glioblastoma model. Cancer Gene Ther 20:544-551, 2013

46. Hynynen K, McDannold N, Sheikov NA, Jolesz FA, Vykhodtseva N: Local and reversible blood-brain barrier disruption by noninvasive focused ultrasound at frequencies suitable for trans-skull sonications. Neuroimage 24:12-20, 2005

47. Hynynen K, McDannold N, Vykhodtseva N, Jolesz FA: Noninvasive opening of BBB by focused ultrasound. Acta Neurochir Suppl 86:555-558, 2003

48. Hynynen K, McDannold N, Vykhodtseva N, Jolesz FA: Noninvasive MR imaging-guided focal opening of the bloodbrain barrier in rabbits. Radiology 220:640-646, 2001

49. Hynynen K, McDannold N, Vykhodtseva N, Raymond S, Weissleder R, Jolesz FA, et al: Focal disruption of the bloodbrain barrier due to $260-\mathrm{kHz}$ ultrasound bursts: a method for molecular imaging and targeted drug delivery. J Neurosurg 105:445-454, 2006

50. Inamura T, Black KL: Bradykinin selectively opens bloodtumor barrier in experimental brain tumors. J Cereb Blood Flow Metab 14:862-870, 1994

51. Jalali S, Huang Y, Dumont DJ, Hynynen K: Focused ultrasound-mediated bbb disruption is associated with an increase in activation of AKT: experimental study in rats. BMC Neurol 10:114, 2010
52. Jones PM, George AM: The ABC transporter structure and mechanism: perspectives on recent research. Cell Mol Life Sci 61:682-699, 2004

53. Jones RM, O'Reilly MA, Hynynen K: Transcranial passive acoustic mapping with hemispherical sparse arrays using CT-based skull-specific aberration corrections: a simulation study. Phys Med Biol 58:4981-5005, 2013

54. Joshi S, Singh-Moon R, Wang M, Chaudhuri DB, Ellis JA, Bruce JN, et al: Cationic surface charge enhances early regional deposition of liposomes after intracarotid injection. J Neurooncol 120:489-497, 2014

55. Juliano RL, Ling V: A surface glycoprotein modulating drug permeability in Chinese hamster ovary cell mutants. Biochim Biophys Acta 455:152-162, 1976

56. Juratli TA, Schackert G, Krex D: Current status of local therapy in malignant gliomas-a clinical review of three selected approaches. Pharmacol Ther 139:341-358, 2013

57. Kaye EA, Chen J, Pauly KB: Rapid MR-ARFI method for focal spot localization during focused ultrasound therapy. Magn Reson Med 65:738-743, 2011

58. Kemper EM, Boogerd W, Thuis I, Beijnen JH, van Tellingen $\mathrm{O}$ : Modulation of the blood-brain barrier in oncology: therapeutic opportunities for the treatment of brain tumours? Cancer Treat Rev 30:415-423, 2004

59. Kioi M, Husain SR, Croteau D, Kunwar S, Puri RK: Convection-enhanced delivery of interleukin-13 receptor-directed cytotoxin for malignant glioma therapy. Technol Cancer Res Treat 5:239-250, 2006

60. Krauze MT, Forsayeth J, Yin D, Bankiewicz KS: Convectionenhanced delivery of liposomes to primate brain. Methods Enzymol 465:349-362, 2009

61. Kreisl WC, Liow JS, Kimura N, Seneca N, Zoghbi SS, Morse $\mathrm{CL}$, et al: P-glycoprotein function at the blood-brain barrier in humans can be quantified with the substrate radiotracer 11C-N-desmethyl-loperamide. J Nucl Med 51:559-566, 2010

62. Kunwar S: Convection enhanced delivery of IL13-PE38QQR for treatment of recurrent malignant glioma: presentation of interim findings from ongoing phase 1 studies. Acta Neurochir Suppl 88:105-111, 2003

63. Kunwar S, Pai LH, Pastan I: Cytotoxicity and antitumor effects of growth factor-toxin fusion proteins on human glioblastoma multiforme cells. J Neurosurg 79:569-576, 1993

64. Kutcher ME, Herman IM: The pericyte: cellular regulator of microvascular blood flow. Microvasc Res 77:235-246, 2009

65. Lampidis TJ, Krishan A, Planas L, Tapiero H: Reversal of intrinsic resistance to adriamycin in normal cells by verapamil. Cancer Drug Deliv 3:251-259, 1986

66. Larsson HB, Stubgaard M, Frederiksen JL, Jensen M, Henriksen O, Paulson OB: Quantitation of blood-brain barrier defect by magnetic resonance imaging and gadolinium-DTPA in patients with multiple sclerosis and brain tumors. Magn Reson Med 16:117-131, 1990

67. Lemasson B, Serduc R, Maisin C, Bouchet A, Coquery N, Robert $\mathrm{P}$, et al: Monitoring blood-brain barrier status in a rat model of glioma receiving therapy: dual injection of lowmolecular-weight and macromolecular MR contrast media. Radiology 257:342-352, 2010

68. Leweke F, Damian MS, Schindler C, Schachenmayr W: Multidrug resistance in glioblastoma. Chemosensitivity testing and immunohistochemical demonstration of P-glycoprotein. Pathol Res Pract 194:149-155, 1998

69. Li XT, Ju RJ, Li XY, Zeng F, Shi JF, Liu L, et al: Multifunctional targeting daunorubicin plus quinacrine liposomes, modified by wheat germ agglutinin and tamoxifen, for treating brain glioma and glioma stem cells. Oncotarget 5:64976511,2014

70. Liebner S, Fischmann A, Rascher G, Duffner F, Grote EH, Kalbacher H, et al: Claudin-1 and claudin-5 expression and tight junction morphology are altered in blood vessels of hu- 
man glioblastoma multiforme. Acta Neuropathol 100:323331,2000

71. Liu HL, Hua MY, Chen PY, Chu PC, Pan CH, Yang HW, et al: Blood-brain barrier disruption with focused ultrasound enhances delivery of chemotherapeutic drugs for glioblastoma treatment. Radiology 255:415-425, 2010

72. Liu LB, Xue YX, Liu YH: Bradykinin increases the permeability of the blood-tumor barrier by the caveolae-mediated transcellular pathway. J Neurooncol 99:187-194, 2010

73. Marquet F, Tung YS, Teichert T, Ferrera VP, Konofagou EE: Noninvasive, transient and selective blood-brain barrier opening in non-human primates in vivo. PLoS ONE 6: e22598, 2011

74. Matsumoto T, Tani E, Kaba K, Shindo H, Miyaji K: Expression of P-glycoprotein in human glioma cell lines and surgical glioma specimens. J Neurosurg 74:460-466, 1991

75. McDannold N, Arvanitis CD, Vykhodtseva N, Livingstone MS: Temporary disruption of the blood-brain barrier by use of ultrasound and microbubbles: safety and efficacy evaluation in rhesus macaques. Cancer Res 72:3652-3663, 2012

76. McDannold N, Vykhodtseva N, Raymond S, Jolesz FA, Hynynen K: MRI-guided targeted blood-brain barrier disruption with focused ultrasound: histological findings in rabbits. Ultrasound Med Biol 31:1527-1537, 2005

77. Mei J, Cheng Y, Song Y, Yang Y, Wang F, Liu Y, et al: Experimental study on targeted methotrexate delivery to the rabbit brain via magnetic resonance imaging-guided focused ultrasound. J Ultrasound Med 28:871-880, 2009

78. Morikawa S, Baluk P, Kaidoh T, Haskell A, Jain RK, McDonald DM: Abnormalities in pericytes on blood vessels and endothelial sprouts in tumors. Am J Pathol 160:985-1000, 2002

79. Nagpal S: The role of BCNU polymer wafers (Gliadel) in the treatment of malignant glioma. Neurosurg Clin N Am 23:289-295, ix, 2012

80. Nakagawa H, Groothuis D, Blasberg RG: The effect of graded hypertonic intracarotid infusions on drug delivery to experimental RG-2 gliomas. Neurology 34:1571-1581, 1984

81. Nance EA, Woodworth GF, Sailor KA, Shih TY, Xu Q, Swaminathan G, et al: A dense poly(ethylene glycol) coating improves penetration of large polymeric nanoparticles within brain tissue. Sci Transl Med 4:149ra119, 2012

82. Nduom EK, Yang C, Merrill MJ, Zhuang Z, Lonser RR: Characterization of the blood-brain barrier of metastatic and primary malignant neoplasms. J Neurosurg 119:427-433, 2013

83. Neuwelt EA, Goldman DL, Dahlborg SA, Crossen J, Ramsey F, Roman-Goldstein S, et al: Primary CNS lymphoma treated with osmotic blood-brain barrier disruption: prolonged survival and preservation of cognitive function. J Clin Oncol 9:1580-1590, 1991

84. Parney IF, Kunwar S, McDermott M, Berger M, Prados $\mathrm{M}$, Cha S, et al: Neuroradiographic changes following convection-enhanced delivery of the recombinant cytotoxin interleukin 13-PE38QQR for recurrent malignant glioma. J Neurosurg 102:267-275, 2005

85. Pastan I, Gottesman MM: Multidrug resistance. Annu Rev Med 42:277-286, 1991

86. Patel RR, Mehta MP: Targeted therapy for brain metastases: improving the therapeutic ratio. Clin Cancer Res 13:16751683,2007

87. Patel SJ, Shapiro WR, Laske DW, Jensen RL, Asher AL, Wessels BW, et al: Safety and feasibility of convectionenhanced delivery of Cotara for the treatment of malignant glioma: initial experience in 51 patients. Neurosurgery 56:1243-1253, 2005

88. Pinzón-Daza ML, Salaroglio IC, Kopecka J, Garzòn R, Couraud PO, Ghigo D, et al: The cross-talk between canonical and non-canonical Wnt-dependent pathways regulates P-glycoprotein expression in human blood-brain barrier cells J Cereb Blood Flow Metab 34:1258-1269, 2014
89. Qin DX, Zheng R, Tang J, Li JX, Hu YH: Influence of radiation on the blood-brain barrier and optimum time of chemotherapy. Int J Radiat Oncol Biol Phys 19:1507-1510, 1990

90. Rand RW, Kreitman RJ, Patronas N, Varricchio F, Pastan I, Puri RK: Intratumoral administration of recombinant circularly permuted interleukin-4-Pseudomonas exotoxin in patients with high-grade glioma. Clin Cancer Res 6:21572165,2000

91. Rapoport SI: Advances in osmotic opening of the bloodbrain barrier to enhance CNS chemotherapy. Expert Opin Investig Drugs 10:1809-1818, 2001

92. Rapoport SI: Osmotic opening of the blood-brain barrier: principles, mechanism, and therapeutic applications. Cell Mol Neurobiol 20:217-230, 2000

93. Rapoport SI, Hori M, Klatzo I: Testing of a hypothesis for osmotic opening of the blood-brain barrier. Am J Physiol 223:323-331, 1972

94. Rapoport SI, Robinson PJ: Tight-junctional modification as the basis of osmotic opening of the blood-brain barrier. Ann N Y Acad Sci 481:250-267, 1986

95. Rascher G, Fischmann A, Kröger S, Duffner F, Grote EH, Wolburg H: Extracellular matrix and the blood-brain barrier in glioblastoma multiforme: spatial segregation of tenascin and agrin. Acta Neuropathol 104:85-91, 2002

96. Reese TS, Karnovsky MJ: Fine structural localization of a blood-brain barrier to exogenous peroxidase. J Cell Biol 34:207-217, 1967

97. Roe M, Folkes A, Ashworth P, Brumwell J, Chima L, Hunjan S, et al: Reversal of P-glycoprotein mediated multidrug resistance by novel anthranilamide derivatives. Bioorg Med Chem Lett 9:595-600, 1999

98. Sage MR, Wilson AJ: The blood-brain barrier: an important concept in neuroimaging. AJNR Am J Neuroradiol 15:601-622, 1994

99. Sampson JH, Akabani G, Archer GE, Bigner DD, Berger MS, Friedman AH, et al: Progress report of a Phase I study of the intracerebral microinfusion of a recombinant chimeric protein composed of transforming growth factor (TGF)alpha and a mutated form of the Pseudomonas exotoxin termed PE-38 (TP-38) for the treatment of malignant brain tumors. J Neurooncol 65:27-35, 2003

100. Sampson JH, Akabani G, Friedman AH, Bigner D, Kunwar $\mathrm{S}$, Berger MS, et al: Comparison of intratumoral bolus injection and convection-enhanced delivery of radiolabeled antitenascin monoclonal antibodies. Neurosurg Focus 20(4):E14, 2006

101. Sampson JH, Archer G, Pedain C, Wembacher-Schröder E, Westphal M, Kunwar S, et al: Poor drug distribution as a possible explanation for the results of the PRECISE trial. $\mathbf{J}$ Neurosurg 113:301-309, 2010

102. Sanovich E, Bartus RT, Friden PM, Dean RL, Le HQ, Brightman MW: Pathway across blood-brain barrier opened by the bradykinin agonist, RMP-7. Brain Res 705:125-135, 1995

103. Sarkar G, Curran GL, Sarkaria JN, Lowe VJ, Jenkins RB: Peptide carrier-mediated non-covalent delivery of unmodified cisplatin, methotrexate and other agents via intravenous route to the brain. PLoS ONE 9:e97655, 2014

104. Shang X, Wang P, Liu Y, Zhang Z, Xue Y: Mechanism of low-frequency ultrasound in opening blood-tumor barrier by tight junction. J Mol Neurosci 43:364-369, 2011

105. Sheikov N, McDannold N, Sharma S, Hynynen K: Effect of focused ultrasound applied with an ultrasound contrast agent on the tight junctional integrity of the brain microvascular endothelium. Ultrasound Med Biol 34:1093-1104, 2008

106. Sheikov N, McDannold N, Vykhodtseva N, Jolesz F, Hynynen K: Cellular mechanisms of the blood-brain barrier 
opening induced by ultrasound in presence of microbubbles. Ultrasound Med Biol 30:979-989, 2004

107. Sonabend AM, Carminucci AS, Amendolara B, Bansal M, Leung R, Lei L, et al: Convection-enhanced delivery of etoposide is effective against murine proneural glioblastoma. Neuro Oncol 16:1210-1219, 2014

108. Stupp R, Tonn JC, Brada M, Pentheroudakis G: High-grade malignant glioma: ESMO Clinical Practice Guidelines for diagnosis, treatment and follow-up. Ann Oncol 21 Suppl 5:v190-v193, 2010

109. Szakács G, Paterson JK, Ludwig JA, Booth-Genthe C, Gottesman MM: Targeting multidrug resistance in cancer. Nat Rev Drug Discov 5:219-234, 2006

110. Tamai I, Tsuji A: Transporter-mediated permeation of drugs across the blood-brain barrier. J Pharm Sci 89:1371-1388, 2000

111. Tanner PG, Holtmannspotter M, Tonn JC, Goldbrunner $\mathrm{R}$ : Effects of drug efflux on convection-enhanced paclitaxel delivery to malignant gliomas: technical note. Neurosurgery 61:E880-E882, 2007

112. Thiebaut F, Tsuruo T, Hamada H, Gottesman MM, Pastan I, Willingham MC: Cellular localization of the multidrugresistance gene product P-glycoprotein in normal human tissues. Proc Natl Acad Sci U S A 84:7735-7738, 1987

113. Thomas H, Coley HM: Overcoming multidrug resistance in cancer: an update on the clinical strategy of inhibiting p-glycoprotein. Cancer Contr 10:159-165, 2003

114. Tung YS, Marquet F, Teichert T, Ferrera V, Konofagou EE: Feasibility of noninvasive cavitation-guided blood-brain barrier opening using focused ultrasound and microbubbles in nonhuman primates. Appl Phys Lett 98: 163704, 2011

115. van Wamel A, Kooiman K, Emmer M, ten Cate FJ, Versluis M, de Jong N: Ultrasound microbubble induced endothelial cell permeability. J Control Release 116:e100-e102, 2006

116. VanBavel E: Effects of shear stress on endothelial cells: possible relevance for ultrasound applications. Prog Biophys Mol Biol 93:374-383, 2007

117. Warren K, Jakacki R, Widemann B, Aikin A, Libucha M, Packer R, et al: Phase II trial of intravenous lobradimil and carboplatin in childhood brain tumors: a report from the Children's Oncology Group. Cancer Chemother Pharmacol 58:343-347, 2006

118. Warth A, Kröger S, Wolburg H: Redistribution of aquaporin-4 in human glioblastoma correlates with loss of agrin immunoreactivity from brain capillary basal laminae. Acta Neuropathol 107:311-318, 2004

119. Watkins S, Robel S, Kimbrough IF, Robert SM, EllisDavies G, Sontheimer H: Disruption of astrocyte-vascular coupling and the blood-brain barrier by invading glioma cells. Nat Commun 5:4196, 2014

120. Weber F, Asher A, Bucholz R, Berger M, Prados M, Chang $\mathrm{S}$, et al: Safety, tolerability, and tumor response of IL4-
Pseudomonas exotoxin (NBI-3001) in patients with recurrent malignant glioma. J Neurooncol 64:125-137, 2003

121. Weber FW, Floeth F, Asher A, Bucholz R, Berger M, Prados M, et al: Local convection enhanced delivery of IL4Pseudomonas exotoxin (NBI-3001) for treatment of patients with recurrent malignant glioma. Acta Neurochir Suppl 88:93-103, 2003

122. Wei KC, Chu PC, Wang HY, Huang CY, Chen PY, Tsai $\mathrm{HC}$, et al: Focused ultrasound-induced blood-brain barrier opening to enhance temozolomide delivery for glioblastoma treatment: a preclinical study. PLoS ONE 8:e58995, 2013

123. Wen PY, Kesari S: Malignant gliomas in adults. N Engl J Med 359:492-507, 2008

124. Williams PC, Henner WD, Roman-Goldstein S, Dahlborg SA, Brummett RE, Tableman M, et al: Toxicity and efficacy of carboplatin and etoposide in conjunction with disruption of the blood-brain tumor barrier in the treatment of intracranial neoplasms. Neurosurgery 37:17-28, 1995

125. Wolburg H, Lippoldt A: Tight junctions of the blood-brain barrier: development, composition and regulation. Vascul Pharmacol 38:323-337, 2002

126. Wolburg H, Wolburg-Buchholz K, Kraus J, RascherEggstein G, Liebner S, Hamm S, et al: Localization of claudin-3 in tight junctions of the blood-brain barrier is selectively lost during experimental autoimmune encephalomyelitis and human glioblastoma multiforme. Acta Neuropathol 105:586-592, 2003

127. Woodworth GF, Dunn GP, Nance EA, Hanes J, Brem H: Emerging insights into barriers to effective brain tumor therapeutics. Front Oncol 4:126, 2014

128. Xi G, Robinson E, Mania-Farnell B, Vanin EF, Shim KW, Takao T, et al: Convection-enhanced delivery of nanodiamond drug delivery platforms for intracranial tumor treatment. Nanomedicine (Lond Print) 10:381-391, 2014

129. Yu AS, McCarthy KM, Francis SA, McCormack JM, Lai J, Rogers RA, et al: Knockdown of occludin expression leads to diverse phenotypic alterations in epithelial cells. Am J Physiol Cell Physiol 288:C1231-C1241, 2005

130. Zünkeler B, Carson RE, Olson J, Blasberg RG, DeVroom $\mathrm{H}$, Lutz RJ, et al: Quantification and pharmacokinetics of blood-brain barrier disruption in humans. J Neurosurg 85:1056-1065, 1996

\section{Author Contributions}

Conception and design: Azad, Pan. Acquisition of data: Azad. Analysis and interpretation of data: Azad. Drafting the article: all authors. Critically revising the article: Remington, Wilson, Grant.

\section{Correspondence}

Gerald A. Grant, Stanford University School of Medicine, 300 Pasteur Dr., Stanford, CA 94305. email: ggrant2@stanford.edu. 